\title{
The prevalence and trends in overweight and obesity in Irish adults between 1990 and 2011
}

\author{
Elaine A Boylan ${ }^{1}$, Breige A McNulty ${ }^{1}$, Janette Walton ${ }^{2}$, Albert Flynn², Anne P Nugent ${ }^{1, *}$ \\ and Michael J Gibney ${ }^{\top}$ \\ 'UCD Institute of Food and Health, University College Dublin, Room L2.57, Science Centre South, Belfield, Dublin 4, \\ Republic of Ireland: ${ }^{2}$ School of Food and Nutritional Sciences, University College Cork, Cork, Republic of Ireland
}

Submitted 28 August 2013: Final revision received 11 February 2014: Accepted 10 March 2014: First published online 10 April 2014

\begin{abstract}
Objective: Obesity is a serious public health issue, the prevalence of which is increasing globally. The present study aimed to investigate trends in overweight and obesity in Irish adults between 1990 and 2011.

Design: Anthropometric data from three Irish national food consumption surveys were used to calculate trends in BMI, waist circumference and waist:hip ratio.

Setting: Three cross-sectional food consumption surveys: the Irish National Nutrition Survey (1990), the North/South Ireland Food Consumption Survey (2001) and the National Adult Nutrition Survey (2011).

Subjects: A collective sample of free-living Irish adults ( $n$ 3125), aged 18-64 years. Results: There were significant increases in mean weight, height and BMI from 1990 to 2011. Significant increments were also reported in waist and hip circumferences and waist:hip ratio between 2001 and 2011, with concurrent increases in the proportion of individuals at risk of developing CVD, particularly females aged 18-35 years. In 2011, 23.4\% of the Irish population was classified as obese; with the mean BMI increasing by $1.1 \mathrm{~kg} / \mathrm{m}^{2}$ between 1990 and 2001 and by $0.6 \mathrm{~kg} / \mathrm{m}^{2}$ between 2001 and 2011 .

Conclusions: The present paper characterises obesity levels in Irish adults from 1990 to 2011. Absolute levels of overweight and obesity have increased between these time points. Of concern is the increase in the proportion of young women classified as at risk of CVD, using waist circumference and waist:hip ratio. Effective prevention strategies are needed to avoid further increases.
\end{abstract}

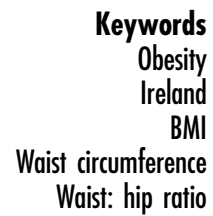

Defined by the WHO as an abnormal or excessive amount of body fat, obesity can have a significant impact on health, such as increasing the risk of CVD, type 2 diabetes, certain cancers and premature mortality ${ }^{(1-5)}$. In addition, excessive body weight can also contribute to debilitating disorders such as osteoarthritis ${ }^{(4)}$. Together with the impact on an individual's health, obesity and the related health disorders also place an economic burden on a population's health-care system, either directly through medical costs or indirectly through lost productivity ${ }^{(4,6)}$. A systematic review of the economic burden of obesity on health-care systems worldwide, from 1990 to 2009, concluded that it cost between $0.7 \%$ and $2 \cdot 8 \%$ of a country's total health-care expenditure ${ }^{(7)}$. In Ireland, it was recently estimated that the total cost of overweight and obesity was $€ 1.13$ billion in $2009^{(8)}$. This was attributed to direct expenses (including general practice, drug and out-patient care) accounting for $35 \%$ of the total cost, while indirect expenses (including absenteeism and premature mortality) accounted for $65 \%$ of the $\operatorname{cost}^{(8)}$.
Globally, the prevalence of overweight and obesity has increased dramatically, doubling or tripling in some countries over the past decade ${ }^{(9)}$. An estimated 502 million people are now classified as obese worldwide ${ }^{(3)}$, with low-, middle- and high-income countries all affected ${ }^{(4,9,10)}$. Recent studies have, however, reported a 'slow down' in the prevalence of obesity in the last decade, suggesting a possible stabilisation of obesity levels ${ }^{(11,12)}$. Flegal et al. analysed the prevalence of obesity from 1999 to 2008 in adults aged $\geq 20$ years in the USA ${ }^{(11)}$. They observed that $32 \%$ of males and $36 \%$ of females were classified as obese between 2007 and 2008, but comparisons over the previous 10 years showed that the increases in obesity prevalence were not continuing at the same rate, particularly for women. Similarly in Italy, the prevalence of obesity was measured between 2001 and 2008 in adults aged 20-99 years and when compared with data from the previous 25 years, a decrease in the prevalence of obesity was observed for both genders, indicating a possible stabilisation $^{(12)}$. More recently, Finucane et al. analysed 
global trends in mean BMI per decade, by region and country from 1980 to 2008, using data from published national health examination surveys and epidemiological studies $^{(10)}$. They reported increases in mean BMI per decade for males and females of $0.4 \mathrm{~kg} / \mathrm{m}^{2}$ and $0.5 \mathrm{~kg} / \mathrm{m}^{2}$, respectively, on average ${ }^{(10)}$. However, flat trends were reported in Central and Eastern Europe and in Central Asia, with a rate of change of $\leq 0.2 \mathrm{~kg} / \mathrm{m}^{2}$ per decade, suggesting that for certain populations, obesity levels may be stabilising. A tendency towards stabilisation of obesity levels in children and adolescents from Australia, European countries such as England and France, and the USA was also documented by Rokholm et al. from 1999 to 2010. In contrast, strong increases were reported in China, Vietnam, India and Maylasia ${ }^{(13)}$.

Despite a possible stabilisation of obesity levels, less clear are the trends in body fat distribution. While BMI is an effective means of categorising obesity, it has limitations for use in population subgroups as it is unable to distinguish between intra-abdominal fat and overall general adiposity ${ }^{(14)}$. Excess intra-abdominal fat is associated with predictors of obesity-related health risk $^{(14-17)}$, with the measures waist circumference (WC) and waist:hip ratio (WHR) used as non-invasive and inexpensive methods of assessing abdominal adiposity ${ }^{(18-20)}$. These measures correlate closely with BMI and some studies have suggested they may be better predictors of disease risk than BMI itself $^{(16,17,19,21-23)}$. Data from the UK have suggested an increase in abdominal obesity, by $17 \%$ for males and $20 \%$ for females, from 1993 to $2008^{(24)}$. This trend has also been observed in other countries, with over half of US adults classified as having abdominal obesity between 2003 and 2004 , the prevalence of which increased by $43 \%$ for males and $31 \%$ for females from 1988 to $2004^{(25)}$.

Regular assessment of obesity patterns is important for planning public health policies and for understanding the impact that changes in obesity rates may have on a population's health. The present study aimed to assess the patterns and distributions of overweight and obesity in Irish adults over the past 20 years using data from three national food surveys: the Irish National Nutrition Survey, 1990; the North/South Ireland Food Consumption Survey, 2001; and the more recent National Adult Nutrition Survey, 2011.

\section{Materials and methods}

\section{Etbical approval}

For each of the three surveys - the Irish National Nutrition Survey (INNS, 1990), the North/South Ireland Food Consumption Survey (NSIFCS, 2001) and the National Adult Nutrition Survey (NANS, 2011) - ethical procedures were followed as appropriate. The INNS was carried out with the full backing and assistance of the Irish Department of Health. The NSIFCS obtained ethical approval from the Federated Dublin Voluntary Hospitals and St. James's
Hospital Joint Research Ethics Committee for the Republic of Ireland, and from the Research Ethical Committee of the University of Ulster for Northern Ireland. The NANS was approved by the Clinical Research Ethics Committee of the Cork Teaching Hospitals, University College Cork and the Human Ethics Research Committee of University College Dublin. All procedures were performed according to the guidelines laid down in the Declaration of Helsinki.

\section{Study design}

The INNS was carried out in the Republic of Ireland between 1988 and 1989 on 715 adults aged 18-90 years, with a response rate of $68 \%{ }^{(26)}$. The NSIFCS was carried out in both Northern Ireland and the Republic of Ireland between 1997 and 1999 on 1379 adults aged 18-64 years, with a response rate of $63 \%{ }^{(27)}$. The NANS was conducted in the Republic of Ireland between 2008 and 2010 on 1500 adults aged $18-90$ years, with a response rate of $60 \%{ }^{(28)}$. All participants were healthy free-living participants, with pregnant or lactating women being excluded. For the purpose of the current study the three survey databases were merged, thus allowing direct comparisons, with only adults aged 18-64 years included ( $n$ 3125). All studies were representative of the population as per the national Census at that time of data collection ${ }^{(29-31)}$. Detailed descriptions of sampling procedures carried out for each survey are published elsewhere ${ }^{(26-28)}$.

\section{Anthropometric measurements}

Anthropometric measurements were carried out in duplicate by trained researchers using standardised methods. NANS also collected self-reported measurements if a measurement by a trained researcher could not be obtained. Height and weight measurements were recorded in all three surveys, while WC and hip circumference (HC) were measured in the NSIFCS and the NANS only. The INNS (1990) recorded weight using a Soèhnle digital personal weighing scales and height using a folding stadiometer (CMS Weighing Equipment, Ltd, London, UK). The NSIFCS (2001) recorded weight using a Seca Alpha 770 digital scale (CMS Weighing Equipment Ltd) and height using a Leicester height measure (CMS Weighing Equipment Ltd). The NANS (2011) recorded weight using a Tanita ${ }^{\circledR}$ model body composition analyser and height with a Leicester portable height measure (Seca, Birmingham, UK). All weighing scales were calibrated and placed on a hard level surface when possible. Participants were asked to remove their shoes, any heavy outdoor clothing, keys, belts and heavy items from pockets before measurement. No allowance was made for weight of clothing. For height measurements, participants removed their shoes and stood upright so heels, buttocks and scapulae were in contact with the back-board and the head was positioned in the Frankfurt plane. WC and HC were measured in duplicate using a nonstretch measuring tape, to the nearest $0 \cdot 1 \mathrm{~cm}$. The waist was measured at the mid-way point between the lower rib 
margin and the iliac crest. Measurements were taken on the naked site when possible. HC was measured at the maximum protuberance of the buttocks, below the iliac crest. Measurements were taken over light clothing. WHR was calculated using an average of the waist and hip circumferences. Waist:height ratio (WHtR) was calculated using an average of the $\mathrm{WC}$ and the single height measure.

For the present analysis, self-reported measurements were removed from the sample, to reduce bias. BMI was calculated using weight $(\mathrm{kg})$ and height squared $\left(\mathrm{m}^{2}\right)$ (weight/height ${ }^{2}$ ) and categorised using the WHO cut-offs ${ }^{(1)}$ : normal weight $\left(\mathrm{BMI}=18.5-24.9 \mathrm{~kg} / \mathrm{m}^{2}\right), \quad$ overweight $\left(B M I=25 \cdot 0-29 \cdot 9 \mathrm{~kg} / \mathrm{m}^{2}\right)$ and obese $\left(\mathrm{BMI} \geq 30 \cdot 0 \mathrm{~kg} / \mathrm{m}^{2}\right)$. Degrees of obesity were also classified; class I (BMI= $\left.30 \cdot 0-34 \cdot 9 \mathrm{~kg} / \mathrm{m}^{2}\right)$, class II (BMI $\left.=35 \cdot 0-39 \cdot 9 \mathrm{~kg} / \mathrm{m}^{2}\right)$ and class III (BMI $\left.\geq 40 \cdot 0 \mathrm{~kg} / \mathrm{m}^{2}\right)^{(1)}$. Categories of WC, determined by Lean $e t a l$. and Han et al., were used to identify those at an increased risk (men, WC $=94-101.9 \mathrm{~cm}$; women, $\mathrm{WC}=80-87.9 \mathrm{~cm}$ ) and high risk (men, $\mathrm{WC} \geq 102 \mathrm{~cm}$; women, WC $\geq 88 \mathrm{~cm}$ ) of $\mathrm{CVD}^{(18,19)}$. Cut-off points of WHR, determined by Lean et al. and Croft et al., were also used to assess a high risk of CVD, defined as WHR $\geq 0.95$ for men and WHR $\geq 0 \cdot 80$ for women ${ }^{(19,20)}$. To characterise the change in obesity levels for the total population, between 1990 and 2001 and between 2001 and 2011, the percentage difference in those classified as normal weight, overweight and obese was also calculated.

\section{Data analysis and statistical methods}

All statistical analysis was carried out using the statistical software package PASW ${ }^{\circledR}$ Version 18. Anthropometric data were normally distributed. Mean and standard deviation were calculated for weight, height, BMI, WC, WHR and WHtR. A general linear model with robust (Huber-White 'sandwich') variance estimators was used to determine any significant changes in mean anthropometric measurements between time points while adjusting for age and sex across surveys. Post hoc pairwise comparisons of surveys were adjusted for multiple comparisons using Holm's sequential Bonferroni procedure. The $\chi^{2}$ test was used to determine significant differences between the percentages of adults within each BMI category across surveys. Significant omnibus $\chi^{2}$ test results gated any post boc $\chi^{2}$ tests to identify the source of the difference. Post hoc tests were conducted, with a Bonferroni correction, to compare all combinations of pooled 'low' $v$. 'high' categories. $P$ values were obtained from Monte Carlo permutation (100 000) of contingency tables. The $\chi^{2}$ test was also used to identify any significant differences in risk categories for WC and WHR. Significance was defined as $P<0.05$.

\section{Results}

Overall, differences in sex were apparent between surveys, with the proportion of males increasing through time in line with the relevant census (INNS $43 \%$ male, NSIFCS $48 \%$ male, NANS $49 \%$ male; $P=0 \cdot 07)^{(29-31)}$. There were also age differences between surveys, with NSIFCS showing an older sample than the other two $(38 \%$ between 18 and 35 years of age, compared with $49 \%$ in INNS and $43 \%$ in NANS; $P<0 \cdot 001)$.

Mean and median anthropometric measurements for Irish adults aged 18-64 years, between 1990 and 2011, are summarised in Table 1. Weight, height and BMI all showed a significant stepwise increase across the three time points, with mean weight increasing by $8.13 \mathrm{~kg}$ for males and $5 \cdot 16 \mathrm{~kg}$ for females over the 20-year period. The greatest increase in weight occurred between 1990 and 2001 (4.9 kg for males and $2.7 \mathrm{~kg}$ for females). In contrast, height had a greater increment between 2001 and $2011(0.02 \mathrm{~m})$ than between 1990 and $2001(0.01 \mathrm{~m})$. When analysed by gender, this stepwise increase in height was evident in males only; a significant increase occurred for females only at $2011(1.63 \mathrm{~m})$ compared with the two previous surveys (1.61 $\mathrm{m}$ at 1990 and $1.62 \mathrm{~m}$ at 2001). In parallel, mean BMI increased $(P<0.001)$ across all time points for the total population. The greatest numerical change occurred between 1990 and 2001 with an increase in BMI of $1 \cdot 1 \mathrm{~kg} / \mathrm{m}^{2}$, with a lesser increment of $0.63 \mathrm{~kg} / \mathrm{m}^{2}$ between 2001 and 2011 . This trend was also observed for males. As mentioned, measures of WC, HC and WHR were available only for 2001 and 2011. Between these years, for the total population, WC increased significantly by $3.78 \mathrm{~cm}(P<0.001)$, HC by $0.82 \mathrm{~cm}(P<0.05)$ and WHR by $0.03(P<0.001)$. In all instances, changes in these measures of body fat distribution were driven by females, with a significant increase in WC $(5.14 \mathrm{~cm} ; P<0.001)$, WHR $(0.04 ; P<0.001)$ and WHtR (0.07; $P<0.001)$ reported. No such changes were observed for males. HC showed a very small difference between surveys (approx. $2 \mathrm{sE}$ ), and the sample size reduction associated with sex-stratified analyses may be responsible for the non-significant results in males and females.

Changes in the prevalence of obesity from 1990 to 2011 are shown in Table 2. Overall, obesity levels increased approximately $2 \cdot 2$ fold for the total population between 1990 and 2011. When examined by gender (excluding underweight), $7 \cdot 8 \%$ of males and $13 \cdot 2 \%$ of females were classified as obese in 1990 , compared with $25.7 \%$ of males and $21.5 \%$ of females in 2011 (increases of 3.3 and 1.6 fold, respectively). The percentage of the total population defined as class II obese $\left(\mathrm{BMI}=35 \cdot 0-39 \cdot 9 \mathrm{~kg} / \mathrm{m}^{2}\right)$ also increased significantly $(P<0.05)$ from $1.4 \%$ in 1990 to $3.6 \%$ in 2011. When split by gender this pattern was no longer significant, but was evident in both males and females and for most age groups. Alongside this, there were significant decreases in the proportion categorised as normal weight $\left(\mathrm{BMI}=18.5-24.9 \mathrm{~kg} / \mathrm{m}^{2}\right)$. For males, levels of normal weight decreased by $7 \cdot 8 \%(P<0.05)$ between 1990 and 2001 and by 10.9\% $(P<0.01)$ between 1990 and 2011. For females, a non-significant decrease of $10 \cdot 0 \%$ in levels of normal weight was observed between 1990 and 2011. 
Table 1 Anthropometric measurements of Irish adults aged 18-64 years between 1990 and $2011^{*}$ for total population, males and females

\begin{tabular}{|c|c|c|c|c|c|c|c|c|c|c|c|c|c|}
\hline & \multicolumn{4}{|c|}{1990} & \multicolumn{4}{|c|}{2001} & \multicolumn{4}{|c|}{2011} & \multirow[b]{2}{*}{$P$ value } \\
\hline & $n$ & Mean & SD & Median & $n$ & Mean & SD & Median & $n$ & Mean & SD & Median & \\
\hline \multicolumn{14}{|l|}{ Total population } \\
\hline Weight (kg) & 590 & $70 \cdot 58^{a}$ & 13.69 & 68.80 & 1369 & $74.88^{\mathrm{b}}$ & $15 \cdot 02$ & 73.60 & 1166 & $77.96^{c}$ & $16 \cdot 49$ & $76 \cdot 10$ & $<0.001$ \\
\hline Height $(m)$ & 590 & $1.67^{\mathrm{a}}$ & 0.09 & 1.66 & 1311 & $1.68^{\mathrm{b}}$ & 0.09 & 1.68 & 1167 & $1.70^{\mathrm{C}}$ & $0 \cdot 10$ & 1.69 & $<0.001$ \\
\hline $\operatorname{BMI}\left(\mathrm{kg} / \mathrm{m}^{2}\right)$ & 590 & $25 \cdot 25^{\mathrm{a}}$ & 4.08 & $24 \cdot 80$ & 1311 & $26 \cdot 35^{\mathrm{b}}$ & 4.46 & $25 \cdot 72$ & 1166 & $26 \cdot 98^{\mathrm{C}}$ & $5 \cdot 10$ & $26 \cdot 24$ & $<0.001$ \\
\hline WC (cm) & - & - & - & - & 1120 & $86 \cdot 97^{\mathrm{a}}$ & $13 \cdot 26$ & $86 \cdot 25$ & 1101 & $90 \cdot 75^{\mathrm{b}}$ & $13 \cdot 78$ & $89 \cdot 15$ & $<0.001$ \\
\hline $\mathrm{HC}(\mathrm{cm})$ & - & - & - & - & 1118 & $102 \cdot 81^{\mathrm{a}}$ & 8.96 & $102 \cdot 05$ & 1100 & $103 \cdot 63^{b}$ & $9 \cdot 67$ & $103 \cdot 10$ & 0.040 \\
\hline WHR & - & - & - & - & 1118 & $0.84^{a}$ & 0.09 & 0.84 & 1100 & $0.87^{b}$ & 0.09 & 0.87 & $<0.001$ \\
\hline $\mathrm{WHtR}$ & - & - & - & - & 1120 & $0.52^{a}$ & 0.73 & 0.51 & 1099 & $0.54^{b}$ & 0.82 & 0.52 & $<0.001$ \\
\hline \multicolumn{14}{|l|}{ Males } \\
\hline Weight $(\mathrm{kg})$ & 256 & $78.09^{a}$ & 12.05 & 77.80 & 655 & $82.94^{\mathrm{b}}$ & $13 \cdot 30$ & $82 \cdot 00$ & 573 & $86 \cdot 22^{C}$ & $15 \cdot 00$ & $85 \cdot 10$ & $<0.001$ \\
\hline Height $(m)$ & 256 & $1.74^{\mathrm{a}}$ & 0.07 & 1.74 & 613 & $1.75^{\mathrm{b}}$ & 0.07 & 1.75 & 575 & $1.77^{\mathrm{c}}$ & 0.07 & 1.77 & $<0.001$ \\
\hline BMI $\left(\mathrm{kg} / \mathrm{m}^{2}\right)$ & 256 & $25 \cdot 74^{\mathrm{a}}$ & 3.43 & 25.55 & 613 & $26 \cdot 93^{b}$ & 3.98 & $26 \cdot 45$ & 573 & $27 \cdot 55^{\mathrm{C}}$ & 4.62 & $27 \cdot 19$ & $<0.001$ \\
\hline WC (cm) & - & - & - & - & 492 & 94.33 & $11 \cdot 32$ & $93 \cdot 15$ & 530 & 95.51 & $12 \cdot 65$ & 95.00 & 0.120 \\
\hline $\mathrm{HC}(\mathrm{cm})$ & - & - & - & - & 491 & $104 \cdot 11$ & $7 \cdot 60$ & $103 \cdot 60$ & 530 & $104 \cdot 64$ & $8 \cdot 28$ & $104 \cdot 45$ & 0.281 \\
\hline WHR & - & - & - & - & 491 & 0.91 & 0.07 & 0.90 & 530 & 0.91 & 0.08 & 0.91 & 0.207 \\
\hline WHtR & - & - & - & - & 492 & 0.54 & 0.66 & 0.53 & 530 & 0.54 & 0.75 & 0.54 & 0.541 \\
\hline \multicolumn{14}{|l|}{ Females } \\
\hline Weight $(\mathrm{kg})$ & 334 & $64 \cdot 82^{\mathrm{a}}$ & 11.99 & 63.00 & 714 & $67 \cdot 49^{b}$ & $12 \cdot 50$ & 65.40 & 593 & $69.98^{\mathrm{C}}$ & $13 \cdot 71$ & $67 \cdot 50$ & $<0.001$ \\
\hline Height $(m)$ & 334 & $1.61^{a}$ & 0.06 & 1.74 & 698 & $1.62^{\mathrm{a}}$ & 0.06 & 1.62 & 594 & $1.63^{b}$ & 0.06 & 1.63 & $<0.001$ \\
\hline BMI $\left(\mathrm{kg} / \mathrm{m}^{2}\right)$ & 334 & $24 \cdot 87^{a}$ & 4.49 & 24.05 & 698 & $25 \cdot 83^{b}$ & 4.79 & $24 \cdot 86$ & 593 & $26 \cdot 43^{\mathrm{C}}$ & $5 \cdot 48$ & $25 \cdot 20$ & $<0.001$ \\
\hline WC (cm) & - & - & - & - & 628 & $81 \cdot 19^{a}$ & $11 \cdot 72$ & $79 \cdot 10$ & 571 & $86 \cdot 33^{b}$ & $13 \cdot 32$ & $83 \cdot 70$ & $<0.001$ \\
\hline $\mathrm{HC}(\mathrm{cm})$ & - & - & - & - & 627 & $101 \cdot 80$ & 9.79 & $100 \cdot 30$ & 570 & $102 \cdot 69$ & $10 \cdot 74$ & 101.50 & 0.140 \\
\hline WHR & - & - & - & - & 627 & $0.80^{\mathrm{a}}$ & 0.07 & 0.79 & 570 & $0.84^{b}$ & 0.08 & 0.84 & $<0.001$ \\
\hline $\mathrm{WHtR}$ & - & - & - & - & 628 & $0.50^{\mathrm{a}}$ & 0.75 & 0.49 & 569 & $0.53^{b}$ & 0.89 & 0.51 & $<0.001$ \\
\hline
\end{tabular}

$n$, sample number; WC, waist circumference; HC, hip circumference; WHR, waist:hip ratio; WHtR, waist:height ratio.

a,b,c Mean values within a row with unlike superscript letters were significantly different $(P<0.05)$; general linear model comparing weight, height, BMI, WC, HC and WHR between 1990, 2001 and 2011, with Holm's sequential Bonferroni post hoc tests used to account for multiple comparisons.

${ }^{*}$ Data for 1990 from Irish National Nutrition Survey (INNS, 1990); data for 2001 from North/South Ireland Food Consumption Survey (NSIFCS, 2001); data for 2011 from National Adult Nutrition Survey (NANS, 2011).

WC, expressed as a percentage of varying levels of CVD risk $^{(18,19)}$ for males and females, is presented in Table 3. Relevant data were not collected in 1990 and so data are presented for 2001 and 2011 only. Compared with 2001, the greatest change was apparent for females, with an increase of $13.6 \%$ in the proportion classed as having a high CVD risk; while an increase of $7.9 \%$ was reported for males. When split by age group, increases of $15.4 \%$ and $16.5 \%$ were observed in the proportions classified as having a high CVD risk for females aged 36-50 years and 51-64 years, respectively. Changes in males were less pronounced; the greatest change was observed for those aged 51-64 years with a decrease of $22.6 \%$ in the proportion categorised as at normal risk and an increase of $21.3 \%$ in those categorised as at high risk.

Table 4 presents WHR data, expressed as a percentage of varying levels of CVD risk ${ }^{(19,20)}$, split by gender. There were decreases in the proportion of males and females classified as having a normal risk of CVD, reflected by an increase in the proportion of those classified as having an increased risk. This trend was more apparent in females (24.4\% increase) than males (12.0\% increase) and in the older age group, with $49 \%$ of all 51-64-year-olds categorised as at increased risk of CVD in 2001 compared with $70 \%$ in 2011 , an increase of $21 \%$. For males, the greatest change occurred in those aged 36-50 years (19.8\% increase), while the greatest change occurred in 18-35-year-old females, with an increase of $25.9 \%$ in the proportion categorised as at increased risk of CVD between 2001 and 2011.

\section{Discussion}

The present study documents, for the first time, trends in obesity levels in Irish adults, aged 18-64 years, between 1990 and 2011. Across this 20-year period, there were significant increases in weight, height and BMI of Irish adults. Significant increases in WC, HC, WHtR and WHR were also observed between 2001 and 2011, with data not available for 1990 . Obesity levels have increased over the last two decades, with $23 \%$ of the Irish population now classified as obese compared with $11 \%$ in 1990, and larger increases were observed for males (18\%) than for females ( $8 \%)$. Changes in mean BMI highlight an increase of $1.1 \mathrm{~kg} / \mathrm{m}^{2}$ occurring between 1990 and 2001 and a lesser increment of $0.6 \mathrm{~kg} / \mathrm{m}^{2}$ occurring between 2001 and 2011 . There appear to have been adverse changes in body fat distribution, particularly in young females, with significant increases in the proportion of the population classified as at increased or high risk of CVD by WC, WHR and WHtR. The greatest changes occurred in females aged 18-35 years, with $54 \%$ now at an increased risk of CVD using WHR as a predictor. 
Table 2 Mean BMI and percentage of Irish adults aged 18-64 years in each BMI category $\left(\mathrm{WHO}^{(1)}\right)^{\star}$ between 1990 and $2011 \dagger$ for total population, males and females

\begin{tabular}{|c|c|c|c|c|c|c|c|c|c|c|c|c|c|c|c|c|c|c|c|}
\hline & \multirow[b]{2}{*}{$n$} & \multicolumn{3}{|c|}{$\begin{array}{c}\text { Normal } \\
\left(\mathrm{BMI}=18 \cdot 5-24.9 \mathrm{~kg} / \mathrm{m}^{2}\right)\end{array}$} & \multicolumn{3}{|c|}{$\begin{array}{c}\text { Overweight } \\
\left(\mathrm{BMI}=25 \cdot 0-29 \cdot 9 \mathrm{~kg} / \mathrm{m}^{2}\right) \\
\end{array}$} & \multicolumn{3}{|c|}{$\begin{array}{c}\text { Obese } \neq \\
\left(\mathrm{BMI} \geq 30.0 \mathrm{~kg} / \mathrm{m}^{2}\right)\end{array}$} & \multicolumn{3}{|c|}{$\begin{array}{c}\text { Obese class I } \\
\left(\mathrm{BMI}=30 \cdot 0-34.9 \mathrm{~kg} / \mathrm{m}^{2}\right)\end{array}$} & \multicolumn{3}{|c|}{$\begin{array}{c}\text { Obese class II } \\
\left(\mathrm{BMI}=35 \cdot 0-39.9 \mathrm{~kg} / \mathrm{m}^{2}\right) \\
\end{array}$} & \multicolumn{3}{|c|}{$\begin{array}{c}\text { Obese class III } \\
\left(\mathrm{BMI} \geq 40.0 \mathrm{~kg} / \mathrm{m}^{2}\right)\end{array}$} \\
\hline & & Mean & SD & $\%$ & Mean & SD & $\%$ & Mean & SD & $\%$ & Mean & SD & $\%$ & Mean & SD & $\%$ & Mean & SD & $\%$ \\
\hline \multicolumn{20}{|c|}{ Total population } \\
\hline 1990 & 580 & $22 \cdot 4$ & 1.6 & $50 \cdot 3$ & $27 \cdot 0$ & 1.4 & 38.8 & $33 \cdot 2$ & 4.0 & 10.9 & 31.8 & 1.3 & 9.0 & $37 \cdot 0$ & $1 \cdot 8$ & 1.4 & $47 \cdot 3$ & 6.5 & 0.5 \\
\hline 2001 & 1301 & $22 \cdot 7$ & 1.6 & $42 \cdot 7$ & $27 \cdot 2$ & 1.4 & $39 \cdot 3$ & 33.5 & 3.7 & $18 \cdot 0$ & 31.7 & 1.4 & $13 \cdot 4$ & $37 \cdot 0$ & 1.3 & $3 \cdot 7$ & $44 \cdot 7$ & $3 \cdot 8$ & 0.9 \\
\hline 2011 & 1158 & $22 \cdot 6$ & 1.5 & $39 \cdot 0$ & $27 \cdot 3$ & 1.4 & 37.4 & $34 \cdot 0$ & 4.6 & 23.6 & $32 \cdot 0$ & 1.4 & $18 \cdot 0$ & $37 \cdot 1$ & $1 \cdot 3$ & 3.6 & $46 \cdot 1$ & $5 \cdot 6$ & $2 \cdot 0$ \\
\hline$P$ value§ & & & & & & & $<0.001$ & & & $<0.001$ & & & & & & 0.007 & & & 0.051 \\
\hline \multicolumn{20}{|l|}{ Males } \\
\hline 1990 & 255 & $22 \cdot 7$ & 1.5 & $41 \cdot 2$ & $27 \cdot 1$ & 1.4 & $51 \cdot 0$ & $33 \cdot 1$ & $2 \cdot 7$ & 7.8 & $32 \cdot 0$ & $1 \cdot 2$ & $6 \cdot 3$ & $35 \cdot 8$ & 0.9 & 1.2 & 41.5 & 0 & 0.4 \\
\hline 2001 & 611 & $23 \cdot 0$ & 1.6 & $33 \cdot 4$ & $27 \cdot 3$ & 1.4 & $46 \cdot 5$ & $32 \cdot 7$ & $3 \cdot 1$ & $20 \cdot 1$ & 31.6 & 1.2 & $16 \cdot 4$ & $36 \cdot 7$ & $1 \cdot 3$ & $3 \cdot 3$ & $45 \cdot 3$ & $5 \cdot 1$ & 0.5 \\
\hline 2011 & 571 & $22 \cdot 8$ & 1.5 & $30 \cdot 3$ & 27.5 & 1.4 & 44.0 & 33.4 & 3.9 & $25 \cdot 7$ & $32 \cdot 0$ & $1 \cdot 3$ & $20 \cdot 8$ & $37 \cdot 1$ & $1 \cdot 3$ & 3.9 & $48 \cdot 1$ & $5 \cdot 6$ & $1 \cdot 1$ \\
\hline$P$ value $\S$ & & & & & & & 0.037 & & & $<0.001$ & & & & & & 0.277 & & & 1 \\
\hline \multicolumn{20}{|l|}{ Females } \\
\hline 1990 & 325 & $22 \cdot 2$ & $1 \cdot 6$ & 57.5 & $26 \cdot 9$ & $1 \cdot 2$ & $29 \cdot 2$ & $33 \cdot 3$ & 4.5 & $13 \cdot 2$ & $31 \cdot 7$ & $1 \cdot 3$ & $11 \cdot 1$ & $37 \cdot 7$ & 1.9 & 1.5 & $50 \cdot 3$ & $5 \cdot 7$ & 0.6 \\
\hline 2001 & 690 & 22.5 & $1 \cdot 6$ & 51.0 & $27 \cdot 1$ & 1.4 & $32 \cdot 9$ & $34 \cdot 3$ & $4 \cdot 2$ & $16 \cdot 1$ & $32 \cdot 0$ & 1.5 & $10 \cdot 7$ & $37 \cdot 2$ & $1 \cdot 3$ & $4 \cdot 1$ & 44.5 & 3.6 & 1.3 \\
\hline 2011 & 587 & 22.5 & 1.5 & 47.5 & $27 \cdot 0$ & 1.4 & 31.0 & 34.7 & $5 \cdot 2$ & 21.5 & $32 \cdot 1$ & 1.6 & $15 \cdot 2$ & $36 \cdot 9$ & 1.4 & $3 \cdot 4$ & 45.4 & 5.5 & $2 \cdot 9$ \\
\hline$P$ value§ & & & & & & & 0.060 & & & 0.013 & & & & & & 0.083 & & & 0.084 \\
\hline
\end{tabular}

$n$, sample number.

${ }^{*}$ Cut-offs used to categorise obesity determined by WHO(1), omitting underweight ( $n$ 28; five males, twenty-three females).

†Data for 1990 from Irish National Nutrition Survey (INNS, 1990); data for 2001 from North/South Ireland Food Consumption Survey (NSIFCS, 2001); data for 2011 from National Adult Nutrition Survey (NANS, 2011).

$\ddagger$ Obese group consists of all three class of obesity $\left(\geq 30 \cdot 0 \mathrm{~kg} / \mathrm{m}^{2}\right)$.
$\S$ Bonferroni-adjusted $P$ values from post hoc comparisons of this category and higher $v$. all lower categories, between time points.

Table 3 Percentage of Irish adults aged 18-64 years, males and females, with varying levels of risk for CVD as defined by waist circumference*, according to age group, in 2001 and $2011 \dagger$

\begin{tabular}{|c|c|c|c|c|c|c|c|c|c|c|c|c|c|c|c|c|}
\hline & \multicolumn{16}{|c|}{ Age group (years) } \\
\hline & \multicolumn{4}{|c|}{$18-64$} & \multicolumn{4}{|c|}{$18-35$} & \multicolumn{4}{|c|}{$36-50$} & \multicolumn{4}{|c|}{$51-64$} \\
\hline & 2001 & 2011 & & & 2001 & 2011 & & & 2001 & 2011 & & & 2001 & 2011 & & \\
\hline & $\%$ & $\%$ & $\%$ change & $P$ value $\ddagger$ & $\%$ & $\%$ & $\%$ change & $P$ value $\neq$ & $\%$ & $\%$ & $\%$ change & $P$ value $\ddagger$ & $\%$ & $\%$ & $\%$ change & $P$ valuef \\
\hline \multicolumn{17}{|l|}{ Males } \\
\hline $\begin{array}{l}n \\
\text { Normal risk }\end{array}$ & $\begin{array}{r}492 \\
52.4\end{array}$ & $\begin{array}{r}530 \\
46.4\end{array}$ & -6.0 & & $\begin{array}{r}198 \\
69.2\end{array}$ & $\begin{array}{r}231 \\
70.6\end{array}$ & 1.4 & & $\begin{array}{r}167 \\
43.1\end{array}$ & $\begin{array}{r}174 \\
36.2\end{array}$ & -6.9 & & $\begin{array}{r}127 \\
38.6\end{array}$ & 125 & 22.6 & \\
\hline Increased risk & $24 \cdot 4$ & $22 \cdot 5$ & -1.9 & 0.108 & 17.7 & 14.7 & -3.0 & - & 29.9 & $28 \cdot 2$ & -1.7 & - & $27 \cdot 6$ & $\begin{array}{l}16 \cdot 0 \\
28 \cdot 8\end{array}$ & $\begin{array}{r}-22 \cdot 0 \\
1.2\end{array}$ & $<0.001$ \\
\hline High risk & 23.2 & $31 \cdot 1$ & 7.9 & 0.009 & $13 \cdot 1$ & 14.7 & 1.6 & - & $26 \cdot 9$ & 35.6 & 8.7 & - & 33.9 & 55.2 & 21.3 & 0.001 \\
\hline \multicolumn{17}{|l|}{ Females } \\
\hline$n$ & 628 & 571 & & & 244 & 234 & & & 251 & 204 & & & 133 & 133 & & \\
\hline Normal risk & 52.4 & $36 \cdot 1$ & $-16 \cdot 3$ & & 68.9 & $49 \cdot 1$ & $-19 \cdot 8$ & & $46 \cdot 2$ & 31.4 & -14.8 & & 33.8 & $20 \cdot 3$ & $-13 \cdot 5$ & \\
\hline Increased risk & 23.9 & $26 \cdot 6$ & $2 \cdot 7$ & $<0.001$ & $16 \cdot 4$ & $26 \cdot 1$ & $9 \cdot 7$ & $<0.001$ & $29 . \overline{5}$ & 28.9 & -0.6 & 0.003 & 27.1 & $24 \cdot 1$ & 3.0 & 0.013 \\
\hline High risk & 23.7 & 37.3 & $13 \cdot 6$ & $<0.001$ & 14.8 & $24 \cdot 8$ & $10 \cdot 0$ & 0.012 & $24 \cdot 3$ & 39.7 & $15 \cdot 4$ & 0.008 & 39.1 & $55 \cdot 6$ & $16 \cdot 5$ & 0.014 \\
\hline
\end{tabular}

n, sample size; WC, waist circumference.

${ }^{*}$ Normal risk: WC $<94 \mathrm{~cm}$ for men and $<80 \mathrm{~cm}$ for women; increased risk: $W C=94-101.9 \mathrm{~cm}$ for men and $80-87.9 \mathrm{~cm}$ for women; high risk: WC $\geq 102 \mathrm{~cm}$ for men and $\geq 88 \mathrm{~cm}$ for women

†Data for 2001 from North/South Ireland Food Consumption Survey (NSIFCS, 2001); data for 2011 from National Adult Nutrition Survey (NANS, 2011).

$\ddagger$ Bonferroni-adjusted $P$ values from post hoc comparisons of this category and higher $v$. all lower risk, between time-points (- indicates test not performed). 
Table 4 Percentage of Irish adults aged 18-64 years, males and females, with varying levels of risk for CVD as defined by waist:hip ratio*, according to age group, in 2001 and $2011 \dagger$

\begin{tabular}{|c|c|c|c|c|c|c|c|c|c|c|c|c|}
\hline & \multicolumn{12}{|c|}{ Age group (years) } \\
\hline & \multicolumn{3}{|c|}{$18-64$} & \multicolumn{3}{|c|}{$18-35$} & \multicolumn{3}{|c|}{$36-50$} & \multicolumn{3}{|c|}{$51-64$} \\
\hline & 2001 & 2011 & & 2001 & 2011 & & 2001 & 2011 & & 2001 & 2011 & \\
\hline & $\%$ & $\%$ & $\%$ change & $\%$ & $\%$ & $\%$ change & $\%$ & $\%$ & $\%$ change & $\%$ & $\%$ & $\%$ change \\
\hline \multicolumn{13}{|l|}{ Males } \\
\hline$n$ & 491 & 530 & & 197 & 231 & & 167 & 174 & & 127 & 125 & \\
\hline Normal risk & $77 \cdot 8$ & $65 \cdot 8$ & $12 \cdot 0$ & $89 \cdot 3$ & 84.8 & 4.5 & $77 \cdot 8$ & $58 \cdot 0$ & $19 \cdot 8$ & $59 \cdot 8$ & $41 \cdot 6$ & $18 \cdot 2$ \\
\hline Increased risk & $22 \cdot 2$ & $34 \cdot 2$ & & $10 \cdot 7$ & $15 \cdot 2$ & & $22 \cdot 2$ & $42 \cdot 0$ & & $40 \cdot 2$ & $58 \cdot 4$ & \\
\hline$P$ value $\ddagger$ & & $<0.001$ & & & 0.170 & & & $<0.001$ & & & 0.004 & \\
\hline \multicolumn{13}{|l|}{ Females } \\
\hline$n$ & 627 & 570 & & 244 & 234 & & 251 & 204 & & 132 & 132 & \\
\hline Normal risk & 57.9 & 33.5 & 24.4 & $72 \cdot 1$ & $46 \cdot 2$ & $25 \cdot 9$ & $52 \cdot 2$ & 28.4 & $23 \cdot 8$ & $42 \cdot 4$ & 18.9 & 23.5 \\
\hline Increased risk & $42 \cdot 1$ & $66 \cdot 5$ & & $27 \cdot 9$ & 53.8 & & $47 \cdot 8$ & 71.6 & & $57 \cdot 6$ & $81 \cdot 1$ & \\
\hline$P$ value $\ddagger$ & & $<0.001$ & & & $<0.001$ & & & $<0.001$ & & & $<0.001$ & \\
\hline
\end{tabular}

n, sample size; WHR, waist:hip ratio.

*Normal risk: WHR $<0.95$ for men and $<0.80$ for women; increased risk: WHR $\geq 0.95$ for men and $\geq 0.80$ for women

†Data for for 2001 from North/South Ireland Food Consumption Survey (NSIFCS, 2001); data for 2011 from National Adult Nutrition Survey (NANS, 2011). †Cross-tabs $\left(\chi^{2}\right)$ test.

In 2011, $26 \%$ of Irish males and $21 \%$ of Irish females were classified as obese. The Survey of Lifestyles, Attitudes and Nutrition in Ireland 2007 (SLÁN 2007) collected anthropometric data on 967 adults aged 18-44 years and classified $16 \%$ of males and $18 \%$ of females as obese ${ }^{(32)}$. Analysis on this same age group with the NANS sample revealed similar obesity rates of $18 \%$ for males and $16 \%$ for females (data not shown). SLÁN also conducted analysis on 1207 adults aged $\geq 45$ years and reported $31 \%$ of males and $32 \%$ of females as obese. Again, when this age group was isolated in NANS, broadly similar figures were obtained, albeit slightly higher for males (38\%) than for females (29\%; data not shown). Overall, both NANS and SLÁN indicate that approximately one-quarter of the Irish population is currently obese. These rates are also similar to those from the UK National Diet and Nutrition Survey (NDNS), published in 2011, where $27 \%$ of males and $25 \%$ of females, aged 19-64 years, were classified as obese using the same established categories ${ }^{(33)}$.

The possibility of a 'slow down' in the rate at which obesity levels are increasing has been recently reported for England $^{(13)}$. A systematic literature review conducted by Rokholm et al. observed that while there appeared to be an increasing prevalence in pregnant women, among the general population there were signs of a levelling off of obesity between 1991 and 2006, for both men (8\% increase) and women $(6 \% \text { increase })^{(13,34)}$. Furthermore, studies such as that by Finucane et al. reported flat trends in BMI in Central and Eastern Europe, with an increase of $\leq 0.2 \mathrm{~kg} / \mathrm{m}^{2}$ per decade ${ }^{(10)}$. Our data suggest that the rate of increase in obesity levels observed in the Irish population is broadly similar over the last 30 years, with an increase of $7 \%$ in obesity levels between 1990 and 2001 and a slightly lesser increment of 6\% between 2001 and 2010. When expressed as BMI change per decade, BMI increased by $1.7 \mathrm{~kg} / \mathrm{m}^{2}$ in the last two decades for Irish adults aged 18-64 years. Numerically, the greatest increase occurred between 1990 and $2001\left(1 \cdot 1 \mathrm{~kg} / \mathrm{m}^{2}\right)$ with a lesser increment of $0.6 \mathrm{~kg} / \mathrm{m}^{2}$ occurring between 2001 and 2011 . However, age and gender differences in population composition contributed to the lack of statistical significance observed when comparing the rate of increase across the three crosssectional population samples included in the present study. Overall, our data suggest that obesity continues to be a public health concern in Ireland. Further research, ideally longitudinal in nature, is required to establish whether the rate of increase in obesity levels in Ireland has slowed down as per other EU countries.

While BMI is a good indicator for assessing overweight and obesity levels, WC and WHR have been reported to provide more information on the distribution of body fat and so may be better indicators of obesity-related health risks such as CVD, insulin resistance and type 2 diabetes $^{(17,35,36)}$. In the current study, average WC for Irish males was $95.5 \mathrm{~cm}$ and for females was $86.3 \mathrm{~cm}$. These findings are similar to those from the most recent NDNS survey in the UK, where mean WC for males was $96.8 \mathrm{~cm}$ and for females, $87.5 \mathrm{~cm}^{(33)}$, but lower than those recorded in the National Health and Nutrition Examination Survey (NHANES) in the USA for adults aged $\geq 20$ years $(100 \cdot 4 \mathrm{~cm}$ for males and $94.0 \mathrm{~cm}$ for females) ${ }^{(25)}$. The greatest increases in the Irish population were observed for females, with $67 \%$ of all females measured now classified as having a WHR $\geq 0 \cdot 80$. In the UK, $29 \%$ of females aged 19-64 years had a WHR $>0 \cdot 85$, a more conservative cut-off than the one used in the present study ${ }^{(33)}$. It should be noted that when the higher WHR cut-off $(>0.85)$ was applied to our data, $31 \%$ of Irish women were considered to be at risk, similar to the proportion reported in the UK. The increase in the number of Irish females of 
childbearing age with WHR $\geq 0 \cdot 80$ (54\% of $18-35$-yearolds) is of particular concern due to the potential implications of obesity in pregnancy. Maternal obesity has been associated with an increased risk of adverse pregnancy outcomes, such as gestational diabetes and postpartum haemorrhage ${ }^{(37-39)}$, while CVD in pregnancy is the most common cause of maternal mortality ${ }^{(40)}$. Strategies are urgently needed to prevent further weight gain in this age group and to increase awareness of the influence of body fat distribution on health.

The present study also highlights differences in the sensitivities and suitability of the various anthropometric measurements used to assess obesity-related health risks. Simply focusing on obesity and relying on BMI as a measure of disease (obesity) risk would have failed to acknowledge the serious health risks associated with carrying excess weight centrally, namely CVD, insulin sensitivity and the metabolic syndrome ${ }^{(16,17,41-45)}$. For example, in NANS, $21.5 \%$ of women aged 18-64 years were classified as obese, yet $37.3 \%$ were classified as high risk using WC as a measure and $66.5 \%$ were classified as high risk using WHR. Hence, simply relying on BMI or WC would have underestimated the true proportion of females at disease risk. In addition, although CVD risk increases with age (this trend being apparent for males as well as for females), greater proportions of women (54-81\%) were deemed to be at high risk using WHR than men (15-58\%) at any age. Gender differences in body fat distribution are well described, as is the redistribution of body fat that occurs with ageing ${ }^{(46,47)}$. However, the present paper suggests that prior to commencing any assessment of overweight and obesity, consideration needs to be given to the population group under study and that a combination of all of the above measures may be more appropriate rather than relying on a single measure.

A major strength of the current study includes the use of objective anthropometric data collected from three national food surveys in representative samples of Irish adults, to assess the trends in obesity prevalence. Methodological similarities between the surveys allowed for direct comparisons of secular trends in obesity across a 20year period. However, statistically significant differences in population composition regarding age and gender resulted in a reduced ability to detect whether rates of increase in obesity had truly increased or stabilised. It should also be noted that adults over the age of 64 years were excluded due to the lack of data collected at earlier time points. In 2011 for adults aged $\geq 65$ years, $25 \%$ of males and $24 \%$ of females were classified as obese ${ }^{(48)}$, broadly similar to that reported for $18-64$-year-olds ( $26 \%$ of males and $21 \%$ of females). Comparisons with the previous years would have given a more comprehensive picture of obesity trends in Ireland and while BMI may not always be appropriate to use in the elderly, it may have given a broad indication of trends in this age group ${ }^{(9)}$. Furthermore, measures of body fat distribution were available only for 2001 and 2011, hence analysis of changes in body fat distribution and associated health risks are limited. Data from time points other than the ones presented would also allow for stronger interpretation of the trends associated with WC and WHR.

\section{Conclusion}

In conclusion, levels of overweight and obesity remain high in Ireland, with considerable increases in the proportion of women deemed to be at a high risk of developing CVD, as defined by WC and WHR. These data reinforce current public health campaigns aimed at decreasing abdominal obesity and reducing the risk of disorders such as CVD. The use of WC and WHR measurements in classifying those at risk of a chronic illness also suggests that BMI should not be relied upon as a single measure of adiposity. Prevention strategies are needed to ensure these levels of overweight and obesity do not continue to rise.

\section{Acknowledgements}

Acknowledgement: The authors wish to acknowledge the advice of Dr Ricardo Segurado, Statistican at CStar (http:// www.Cstar.ie), on statistical components of the study. Financial support: This study was funded by the Irish Department of Agriculture, Food and the Marine and the Health Research Board under their joint Food for Health Research Initiative (2007-12) (grant number 7FHRIUCC2). The Irish Department of Agriculture, Food and the Marine and the Health Research Board had no role in the design, analysis or writing of this article. Conflict of interest: None. Authorship: M.J.G. and A.F. were involved in conception of the work and are grant holders. B.A.M., A.P.N., A.F, J.W. and M.J.G. contributed to the design and implementation of the study and preparation of the manuscript. E.A.B. was involved in subject recruitment, data collection, data analysis and manuscript preparations. All authors reviewed and approved the final manuscript. Ethics of human subject participation: Ethical approval was obtained from the following: the Irish Department of Health; the Federated Dublin Voluntary Hospitals and St. James's Hospital Joint Research Ethics Committee for the Republic of Ireland, and the Research Ethical Committee of the University of Ulster for Northern Ireland; the Clinical Research Ethics Committee of the Cork Teaching Hospitals, University College Cork and the Human Ethics Research Committee of University College Dublin.

\section{References}

1. World Health Organization (2000) Obesity: Preventing and Managing the Global Epidemic: Report of a WHO Consultation. WHO Technical Report Series no. 894. Geneva: WHO. 
2. Romero-Corral A, Montori VM, Somers VK et al. (2006) Association of bodyweight with total mortality and with cardiovascular events in coronary artery disease: a systematic review of cohort studies. Lancet 368, 666-678.

3. Swinburn BA, Sacks G, Hall KD et al. (2011) The global obesity pandemic: shaped by global drivers and local environments. Lancet 378, 804-814.

4. Wang YC, McPherson K, Marsh T et al. (2011) Health and economic burden of the projected obesity trends in the USA and the UK. Lancet 378, 815-825.

5. Levy DT, Mabry PL, Wang YC et al. (2011) Simulation models of obesity: a review of the literature and implications for research and policy. Obes Rev 12, 378-394.

6. Fry J \& Finley W (2005) The prevalence and costs of obesity in the EU. Proc Nutr Soc 64, 359-362.

7. Withrow D \& Alter DA (2011) The economic burden of obesity worldwide: a systematic review of the direct costs of obesity. Obes Rev 12, 131-141.

8. Safefood (2012) The Cost of Overweight and Obesity on the Island of Ireland. Cork: Safefood.

9. World Health Organization (2003) Diet, Nutrition and the Prevention of Chronic Diseases. Report of a Joint WHO/FAO Expert Consultation. WHO Technical Report Series no. 916. Geneva: WHO.

10. Finucane MM, Stevens GA, Cowan MJ et al. (2011) National, regional and global trends in body-mass index since 1980: systematic analysis of health examination surveys and epidemiological studies with 960 country-years and $9 \cdot 1$ million participants. Lancet 377, 557-567.

11. Flegal KM, Carroll MD, Ogden CL et al. (2010) Prevalence and trends in obesity among US adults, 1999-2008. JAMA 303, 235-241.

12. Micciolo R, Di Francesco V, Fantin F et al. (2010) Prevalence of overweight and obesity in Italy (2001-2008): is there a rising obesity epidemic? Ann Epidemiol 20, 258-264.

13. Rokholm B, Baker JL \& Sorensen TI (2010) The levelling off of the obesity epidemic since the year 1999 - a review of evidence and perspectives. Obes Rev 11, 835-846.

14. Romero-Corral A, Somers VK, Sierra-Johnson J et al. (2008) Accuracy of body mass index in diagnosing obesity in the adult general population. Int J Obes (Lond) $\mathbf{3 2}$, 959-966.

15. Zhu S, Wang Z, Heshka S et al. (2002) Waist circumference and obesity-associated risk factors among whites in the third National Health and Nutrition Examination Survey: clinical action thresholds. Am J Clin Nutr 76, 743-749.

16. Dalton M, Cameron AJ, Zimmet PZ et al. (2003) Waist circumference, waist-hip ratio and body mass index and their correlation with cardiovascular disease risk factors in Australian adults. J Intern Med 254, 555-563.

17. Janssen I, Katzmarzyk PT \& Ross R (2004) Waist circumference and not body mass index explains obesityrelated health risk. Am J Clin Nutr 79, 379-384.

18. Han TS, van Leer EM, Seidell JC et al. (1995) Waist circumference action levels in the identification of cardiovascular risk factors: prevalence study in a random sample. BMJ 311, 1401-1405.

19. Lean MEJ, Han TS \& Morrison CE (1995) Waist circumference as a measure for indicating need for weight management. BMJ 311, 58-61.

20. Croft JB, Keenan NL, Sheridan DP et al. (1995) Waist-to-hip ratio in a biracial population: measurement, implications and cautions for using guidelines to define high risk for cardiovascular disease. J Am Diet Assoc 95, 60-64.

21. Ashwell M \& Gibson S (2009) Waist to height ratio is a simple and effective obesity screening tool for cardiovascular risk factors: analysis of data from the British National Diet and Nutrition Survey of adults aged 19-64 years. Obes Facts 2, 97-103.
22. Pischon T, Boeing H, Hoffmann K et al. (2008) General and abdominal adiposity and risk of death in Europe. $N$ Engl $J$ Med 359, 2105-2120.

23. Seidell JC, Pérusse L, Després JP et al. (2001) Waist and hip circumferences have independent and opposite effects on cardiovascular disease risk factors: the Quebec Family Study. Am J Clin Nutr 74, 315-321.

24. Howel D (2012) Trends in the prevalence of abdominal obesity and overweight in English adults (1993-2008). Obesity (Silver Spring) 20, 1750-1752.

25. Li C, Ford ES, McGuire LC et al. (2007) Increasing trends in waist circumference and abdominal obesity among US adults. Obesity (Silver Spring) 15, 216-216.

26. Lee P \& Cunningham K (1990) Irish National Nutrition Survey. Dublin: Irish Nutrition and Dietetic Institute.

27. Harrington KE, Robson PJ, Kiely M et al. (2001) The North/ South Ireland Food Consumption Survey: survey design and methodology. Public Health Nutr 4, 1037-1042.

28. Irish Universities Nutrition Alliance (2011) National Adult Nutrition Survey Summary Report. http://www.iuna.net/? $\mathrm{p}=106$ (accessed April 2013).

29. Central Statistics Office (1986) Census 1986 Volume 1. Dublin: The Stationery Office.

30. Central Statistics Office (1996) Census 1996 Principal Demographic Results. Dublin: The Stationery Office.

31. Central Statistics Office (2011) Census 2011 Preliminary Report. Cork: Central Statistics Office; available at http://www.cso.ie/en/census/census2011reports/census2011 preliminaryreport/

32. Morgan K, McGee H, Watson D et al. (2008) SLÁN 2007: Survey of Lifestyle, Attitudes and Nutrition in Ireland. Dietary Habits of the Irish Population. Dublin: Department of Health and Children.

33. Department of Health (2011) National Diet and Nutrition Survey Headline Results from Years 1 and 2 (combined) of the Rolling Programme (2008/09-2009/10). https://www. gov.uk/government/publications/national-diet-and-nutritionsurvey-headline-results-from-years-1-and-2-combined-of-therolling-programme-2008-9-2009-10 (accessed April 2013).

34. Howel D (2011) Trends in the prevalence of obesity and overweight in English adults by age and birth cohort, 1991-2006. Public Health Nutr 14, 27-33.

35. Czernichow S, Kengne AP, Stamatakis E et al. (2011) Body mass index, waist circumference and waist-hip ratio: which is the better discriminator of cardiovascular disease mortality risk? Evidence from an individual-participant metaanalysis of 82864 participants from nine cohort studies. Obes Rev 12, 680-687.

36. Yusuf S, Hawken S, Ounpuu S et al. (2005) Obesity and the risk of myocardial infarction in 27,000 participants from 52 countries: a case-control study. Lancet 366, 1640-1649.

37. Sebire NJ, Jolly M, Harris JP et al. (2001) Maternal obesity and pregnancy outcome: a study of 287,213 pregnancies in London. Int J Obes Relat Metab Disord 25, 1175-1182.

38. Edwards LE, Dickes WF, Alton IR et al. (1978) Pregnancy in the massively obese: course, outcome, and obesity prognosis of the infant. Am J Obstet Gynecol 131, 479-483.

39. Bianco AT, Smilen SW, Davis Y et al. (1998) Pregnancy outcome and weight gain recommendations for the morbidly obese woman. Obstet Gynecol 91, 97-102.

40. Moghbeli N, Pare E \& Webb G (2008) Practical assessment of maternal cardiovascular risk in pregnancy. Congenit Heart Dis 3, 308-316.

41. Iyer A \& Brown L (2010) Lipid mediators and inflammation in glucose intolerance and insulin resistance. Drug Discov Today 7, 3-4.

42. Dixon JB (2010) The effect of obesity on health outcomes. Mol Cell Endocrinol 316, 104-108. 
43. Trayhurn P \& Wood IS (2004) Adipokines: inflammation and the pleiotropic role of white adipose tissue. Br J Nutr $\mathbf{9 2}$, 347-355.

44. Fontana L, Eagon JC, Trujillo ME et al. (2007) Visceral fat adipokine secretion is associated with systemic inflammation in obese humans. Diabetes 56, 1010-1013.

45. Despres JP, Moorjani S, Lupien PJ et al. (1990) Regional distribution of body fat, plasma lipoproteins, and cardiovascular disease. Arteriosclerosis 10, 497-511.
46. Stevens J, Katz EG \& Huxley RR (2010) Association between gender, age and waist circumference. Eur J Clin Nutr 64, 6-15.

47. Cartwright MJ, Tchkonia T \& Kirkland JL (2007) Aging in adipocytes: potential impact of inherent, depot-specific mechanisms. Exp Gerontol 42, 463-471.

48. Boylan EA, McNulty BA, Walton J et al. (2011) Analysis of the anthropometric data of adults aged $65+$ years participating in the National Adult Nutrition Survey. Proc Nutr SOC 70, OCE3, E51. 